\title{
Influence of the Order of Provided Information on the First Impression
}

\author{
Miranda Giorgashvili \\ School of Humanitarian and Social Science, Tbilisi Open University, Tbilisi, Georgia \\ Email: miranda.giorgashvili@tsu.ge
}

How to cite this paper: Giorgashvili, M. (2021). Influence of the Order of Provided Information on the First Impression. Psychology, 12, 1799-1824.

https://doi.org/10.4236/psych.2021.1211109

Received: October 4, 2021

Accepted: November 22, 2021

Published: November 25, 2021

Copyright (c) 2021 by author(s) and Scientific Research Publishing Inc. This work is licensed under the Creative Commons Attribution International License (CC BY 4.0).

http://creativecommons.org/licenses/by/4.0/

\section{(c) (i) Open Access}

\begin{abstract}
The study aims to explore the dominance of stereotypic thinking in the process of social information processing. It tests one of the assumptions of Parallel Constraint Satisfaction Theory regarding the order of provided information. It is hypothesized that dominance of either type of processing (stereotypic or individuating) depends on the primacy of provided social information. In the experiment, each participant $(\mathrm{N}=144)$ was randomly assigned to either of the condition, where one was presented with one and the same stereotypic (categorical) and individuating (counter stereotypic behavioral) information about one and the same person, provided into a certain order. Based on the level of $p<0.05$, comparison of impressions received in different order conditions (category primacy vs. behavior primacy) revealed that the first impressions followed the effect of primacy. This effect appeared to be consistent in the impressions of both observed targets (Doctor and IT). Hypothesis about the importance of order and primacy in social perception has been proved, but hypothesis about averaging impression in the condition of the information being provided together was not proved. The study shows that order of provided information determines whether target instantly stereotypically categorizes others or focuses more on their behavior and makes individualistic impression of them.
\end{abstract}

\section{Keywords}

Information Processing, Stereotypes, Categorization, Individuation, First Impression, Connectionist Network

\section{Introduction}

Stereotypical thinking is an integral part of our daily lives. It is an essential mechanism for our adaptation, but when operating in social world, observers due to stereotypic perception sacrifice others' uniqueness and also realistic understanding of others' behaviors and individual characteristics. Often the basis for dis- 
crimination in social relations is precisely the wrong stereotypical perception. It seems stereotypical thinking really has a big impact on us. It determines our attitude towards the world, our relationships with other individuals, and ultimately, our psychological well-being, both on an individual and societal level.

How can it be explained that stereotypical thinking, despite its negative effects, is still the main direction of our thinking? Studies in social psychology have long shown that stereotyping ensures economical and rapid processing of information, which is so important in fast and informatively overwhelmed everyday life (Fiske, 1988; Fiske \& Pavelchak, 1986; Fiske et al., 1987; Locksley, Hepburn, \& Ortiz, 1982; Macrae \& Bodenhausen, 2001). Although being that much necessary, stereotypic categorization frequently leads society toward discrimination against others on the basis of sex, age, ethnos, race, profession, religion, occupation and other social characteristics. Evaluating others competence, traits and abilities due to their gender and ethnicity, assigning criminal or aggressive behavior to certain ethnicity and race, sharing future benefits based on other's religious affiliation or gender or simply interpreting other's ordinal behavior from the lens of skin color are those few instances of discrimination which are widely presented in our everyday life.

On 25 November 2007, Ms. Gibbons, 54 years old teacher would not imagine that because of an ordinal class assignment she would be sentenced for offending Islam (Popov, Parker, \& Seath, 2018). Due to her western origin, her behavior related to class assignment was instantly interpreted as offense to Islam by Sudan people (Gettleman, 2007). Such cases raise concerns about discrimination, wanting to find out ways to overcome it. Such cases illustrate how detrimental it is to attend to categorical belonging of the person, rather than to his real, individual characteristics and behaviors. What can we do to avoid discrimination? How person's real, individual characteristics can be perceived along with stereotypic ones? Or how perception of individual characteristics can overcome dominant effect of activated stereotype? These questions are already addressed in psychology empirically; studies show how clear individuating information is able to overcome stereotypic perception, but is it only clearness of individuating information that can overcome twisted perception or there exist some other cognitive mechanisms that may help us in this regard? No matter the clear behavior being presented in the case of Ms. Gibbons, she was still evaluated on the basis of her culture dominantly.

Not taking into consideration person's behavior (which is one of the clear representations of one's individuality), relaying dominantly on stereotypic information is precisely the issue that is addressed in this article. The article presents an experimental study, which aims to test additional cognitive mechanism, which mediates the influence of stereotypic thinking or categorization. The study focuses on the relationship between stereotypic and individuating information and presents order, as the factor determining the dominance of either type of processing.

\section{Theoretical Overview}

Categorization and stereotypic thinking is regarded to be the most dominant 
and automatic process, which takes the first step in information processing of the social world. Even though there are empirical evidences referring to mediated nature of the dominance of categorization, still categorization is thought to be the thinking mode that observer is doomed to rely on. Among the most automatic social categories, which determine observer's everyday perception of others are: gender, age and ethnicity (Gawronski et al., 2003; Fiske \& Neuberg, 1990; Kopetz \& Kruglanski, 2008; Pratto \& Bargh, 1991; Quinn \& Macrae, 2005). Regardless of such automaticity, other empirical results point to factors, which diminish effect of categorization and stereotypic thinking: categorization lessens its power, when the observer has a negative mood or is depressed (Bless, Schwarz, \& Wiekand, 1996; Chartard, Bargh, \& Baaren, 2006), when has strong stereotypical beliefs (toward a certain life issue e.g. ethnicity) (Gawronski et al., 2003), when the target is already known, rather than an unknown person (Quinn et al., 2009), when along with the stereotypic information clear individuating information is presented as well (Baron, Albright, \& Malloy, 1995; Mettrick \& Cowan, 1996; Locksley et al., 1980; Locksley et al., 1982; Kunda \& Sherman-Williams, 1993; Bargh \& Pratto, 1986); in addition, having motivation (Fiske, 1988; Fiske \& Neuberg, 1990; Tobin et al., 2009), or/and having less overwhelmed cognitive apparatus (Bodenhausen \& Lichtenstein, 1987), with enough capacity of attention (Bargh \& Pratto, 1986; Fiske \& Neuberg, 1990) and being aimed at causal thinking (Tobin et al., 2009) also undermine the process of stereotypic thinking.

According to Fiske and Neuberg (1990), all of the above mentioned factors indeed determine to which mode of impression the observer leans to. Information processing, however, always starts from categorization. Even when the observed target does not activate certain clear categorical representation, observer tries to categorize target anyway. Only when the observer is influenced by the above mentioned factors, does he proceed to a more complex and objective form of processing such as individuation (Fiske \& Neuberg, 1990). Basing on the assumptions of Continuum Model, Fiske and colleagues $(1986,1990)$ present categorization as a dominant form of impression, which is always initial step in impression continuum and is the most automatic form of impression.

This assumption about the dominance of categorization (stereotyping) has been strongly criticized by Kunda and Thagard (1996), who propose Parallel Constraint Satisfaction Theory (PSCT) as a model for information processing. According to the authors, impression formation is not a serial process, in which categorization assumes the initial step of the processing. On the contrary, it is the holistic process, in which all kinds of information being observed are processed simultaneously and in parallel (Kunda \& Sherman-William, 1993; Kunda \& Thagard, 1996, 1997). In this process, none of the modes such as categorization or individuation take dominance over each other, but both have an equal status during the process; in everyday life, when both types of information are observed, they jointly influence impression (Kunda \& Thagard, 1996, 1997). The only case, when it is possible to speak about the dominance of categorization or stereotypic impression is when pertinent stereotypic information is received in 
the first place. In the same way, if individuating information is perceived first, then it determines the whole impression (Kunda \& Thagard, 1996).

According to Kopetz and Kruglanski (2008) assumption about primacy effect and the importance of the order had not been tested empirically. Indeed, starting from Asch's classic study, the influence of order on social impression has widely been studied in social psychology (Brink, 1974; Dreben, Fiske, \& Hastie, 1979; Kardes \& Herr, 1990; Nauts et al., 2014), although this did not happen in relationship to stereotypic and individuating mode of processing. Impression formation has also been studied from different perspectives, such as information integration problem (Gollin, 1954), or constraining the meaning of stereotype by provided individuating information (Baron et al., 1995; Beckett \& Park, 1995; Kunda \& Sherman-Williams, 1993; Locksley et al., 1980; Locksley et al., 1982; Mettrick \& Cowan, 1996; Quinn, Mason, \& Macrae, 2009), or integration of contradictory traits or stereotypes (Casselden \& Hampson, 1990; Hastie, Schroeder, \& Weber, 1990) and so on, though there is no clear study that would directly test the influence of primacy on the dominance of stereotypic and individuating information (or processing). In other words there is no study which would manipulate two different types of information-one stereotypic information and the other individuating one-according to certain order. Instead of measuring how two similar types of information are integrated into one coherent impression, it is interesting to see how order effects integration of explicitly given stereotypic and individuating information. By linking Ash's idea about the order and primacy to the relationship between stereotypic and individuating information, we want to uncover one additional factor which could mediate the dominance of stereotypic thinking in forming impression about other.

Stemming from PCST theory, we aim to test one of its assumption related to the order of provided information, according to which the order of information presentation determines the dominance of the information, on which first impression is mostly based on. In particular, information provided in the first place, determines the dominance of categorization or individuation. As the given model of PCST is a computation model, it successfully simulates Asch's classic experiments related to the influence of order of provided adjectives, though real life experiment involving influence of order on stereotypic and individuating processing has not been conducted yet. Connectionist network and the processes of inhibition and excitation effectively simulate results of classic experiments (Kunda \& Thagard, 1996, 1997), however, we wonder what happens when connectionist mechanism is explored in real life circumstances, towards the issue of primacy of stereotypic or individuating information. Based on the model of PCST we aim to test not only its assumption about the order, but the whole model itself. By measuring impression in terms of inhibition and excitation, we want to see how two types of contradictory information constrain each other's meaning under different order conditions. Exploring and using the network of associations as methodology for impression measurement (measuring processes of inhibition and excitation), gives opportunity to study not only the order effect but 
also its underline cognitive mechanism in terms of connectionist network.

\section{Study Overview}

Proceeding from PCST, the aim of the given research is to test the influence of primacy on the dominance of stereotypic or individuating information integrated in formed first impression. In order to study the issue of primacy and its effect on stereotypic thinking we choose the process of impression, which is formed by the observer about an unknown target, based on the visual information received from target's appearance and behavior.

As most of the experiments held on stereotyping and individuation are held on verbal materials, we decided to make exploration on the basis of visually formed impression. According to Bargh (1989) impression based on nonverbal information is regarded to be more authentic, than the impression derived from verbal material. Besides, it is assumed that is much more interesting to see how a person forms impression about the other person, perceiving him in a real life situation (Macrae \& Bodenhausen, 2001).

\subsection{Basic Assumptions}

According to the theory, we assume that the stereotypic information will dominantly lead the impression, if the pertinent stereotypic information is provided first; in the same way, we assume that in case of individuating information being provided first, formed first impression will be dominantly based on individuating information. And finally, when presenting both types of information simultaneously, none of them will lead impression dominantly.

In order to explore the issue we decided to take one and the same type of information about one and the same person and vary it according to different order. The order of presentation was defined into three conditions: 1) condition, when stereotypic information is provided first and then is provided individuating information, 2) condition with reversed order, and 3) condition, when both types of information are provided together. Types of the information varied in the experiment are: stereotypic ${ }^{1}$ and individuating ${ }^{2}$ information.

${ }^{1}$ According to social psychology literature Stereotypic or Categorical Information is the information which refers to membership of target to a certain social group. The most automatically inferred stereotypic information is information based on age, gender, and ethnicity (Fiske \& Neuberg, 1990; Kunda \& Sherman-William, 1993; Kunda \& Thagard, 1996; Gawronski et al., 2003). The other types of stereotypic information is profession, religious affiliation, social role, social status (Andersen \& Klatzky, 1987; Gawronski et al., 2003; Fiske \& Neuberg, 1990; Fiske \& Pavelchak, 1986; Kunda \& Sherman-William, 1993; Kunda \& Thagard, 1996; Quinn, Mason, \& Macrae, 2009). This type of information can be easily activated by visual cues (Fiske \& Neuberg, 1990; Pratto \& Bargh, 1991; Martin \& Macrae, 2007), as well as by verbally shared information.

${ }^{2}$ Individuating Information is the remaining part of information which does not refer to any type of membership to certain social group. It may be biographical data, behavior or information related to trait (Kunda \& Thagard, 1996: p. 235). Besides, this is the information, which in every research held about the stereotypes and individuation, is counter-stereotypic (Baron et al., 1995; Beckett \& Park, 1995; Gawronski et al., 2003; Locksley et al., 1980; Kunda \& Sherman-William, 1993). There is no universal individuating information, as information assumes the function of individuation if it contradicts activated stereotypes in a given situation (Kunda \& Thagard, 1996). Besides, individuating information must be clear and unambiguous in order to strictly contradict activated stereotype, otherwise, its meaning will definitely be constrained by the activated stereotype (Kunda \& Thagard, 1996). 


\subsection{Preliminary Research Steps}

On the basis of literature review and preliminary study, five categories (themes) were selected for stereotypic information, to be applied in experimental study. These categories are: Doctor, Cook, Lecturer, Specialist of Informational Technologies (IT) and Typical Georgian Man (TGM). Most of the selected themes are professional categories, but the one category-TGM-represents social category, not related to profession (Giorgashvili, 2020, 2021).

After choosing categories, we studied stereotypic and individuating characteristics related to the image of each category. According to the survey with open ended questionnaire, conducted on 210 participants (average age 20, SD = 1.3) images of Doctor, IT, Lecturer, Cook and TGM revealed association to a certain set of stereotypic characteristics (Giorgashvili, 2020, 2021). As categories of Lecturer, Cook and TGM were discarded from the study on a later stage, here we provide results related to Doctor and IT only. According to the results, typical image of Doctor appeared to be related more to a male from 36 - 60 age group, who wears uniform and classic outfit and has diverse personal characteristics (Giorgashvili, 2020, 2021) (see Table 1). Typical image of IT represented definitely male person of 21 - 35 age, whose style is more casual and his characteristics speak more about his reticence (Giorgashvili, 2020, 2021) (see Table 2).

Besides stereotypic characteristics, individuating information (characteristics, which do not fit stereotypic image) was also revealed for each category. According to the results of focus groups each category was characterized according to behaviors that contradicted the image of a typical representative (Giorgashvili 2020, 2021). Table 3 represents the list of contradictory behaviors, which in experiment served as individuating behavioral information for given category.

Table 1. Characteristics of a typical doctor.

\begin{tabular}{|c|c|c|c|c|}
\hline Age & Gender & Appearance & Life Interests & Traits \\
\hline $36-5090.0 \%$ & Female $17.0 \%$ & Middle $31.3 \%$ & To heal patients $40.0 \%$ & Organized person at work $27.8 \%$ \\
\hline \multirow[t]{4}{*}{$51-6041.0 \%$} & Male24.0\% & Tall $28.1 \%$ well-built body $31.3 \%$ & Professional interests $37.0 \%$ & Average person $33.3 \%$ \\
\hline & Both $58.0 \%$ & Looks after him/herself $28.1 \%$ & Earn money $27.0 \%$ & Friendly $52.8 \%$ \\
\hline & & Wears uniform $46.0 \%$ & & \\
\hline & & Wears solid/classic $33.0 \%$ & & \\
\hline
\end{tabular}

Hierarchical cluster analysis (Method: between group linkage).

Table 2. Characteristics of a typical IT.

\begin{tabular}{|c|c|c|c|c|}
\hline Age & Gender & Appearance & Life Interests & Traits \\
\hline \multirow[t]{7}{*}{$21-35100 \%$} & Male $90.0 \%$ & Thin $47.4 \%$ & Computers/other gadgets $43.3 \%$ & Sensible $39.0 \%$ \\
\hline & Both 7.5\% & With eyeglasses $36.8 \%$ & Career $36.6 \%$ & Communicable $25.0 \%$ \\
\hline & & Tall $26.3 \%$ & & Reserved $19.4 \%$ \\
\hline & & Medium height $23.7 \%$ & & Not communicable $19.4 \%$ \\
\hline & & Sympathetic $23.7 \%$ & & Tied $20.0 \%$ \\
\hline & & Wears Jeans $52.6 \%$ & & Polite $16.7 \%$ \\
\hline & & Free/casual style cloth $36.9 \%$ & & \\
\hline
\end{tabular}

Hierarchical cluster analysis (Method: between group linkage). 
Table 3. Individuating information contradicting typical stereotyps of IT and doctor.

\begin{tabular}{ll}
\hline \multicolumn{1}{c}{ Doctor } & \multicolumn{1}{c}{ IT } \\
\hline $\begin{array}{l}\text { Interested in soccer, rugby, box, basketball, } \\
\text { karate }\end{array}$ & $\begin{array}{l}\text { Is interested in ballet, theatre, Georgian } \\
\text { folk dance, classic music, poetry }\end{array}$ \\
$\begin{array}{l}\text { Is homosexual } \\
\text { Has tough guy manners }\end{array}$ & Likes Georgia feasts-Georgia weddings \\
Is biker & and traditional parties \\
Is unclean, gentle, fearful & Is gentlemen \\
Watches TV serials & Is homosexual \\
\hline
\end{tabular}

Received categorical descriptions later were reexamined by qualitative study, which aimed to test if the descriptions were commonly shared images of the category in the group of adults of 18 - 23 ages (Giorgashvili, 2020, 2021). By administering questionnaire enrolling 229 descriptive concepts, respondents were asked to evaluate the most typical male member of each five categories on the basis of these concepts (how much it characterized the typical male member of either category). They were reminded to lean on the typical image, which they had in their mind about typical male member of Lecturer, Doctor, IT, Cook and TGM. Evaluation was carried out using 11 point evaluative scale, points of which varied from +5 mostly typical to -5 totally untypical. For statistical analysis given scale became later transferred to 1 - 11 point scale (Giorgashvili, 2020, 2021).

Factor analysis revealed characteristics that were 1) stereotypically associated to either category (receiving evaluations 8 - 11 points), 2) individuating characteristics (receiving evaluations 1 - 4 points), and 3) neutral characteristics, which did not represent typical or un-typical characteristics clearly-factors receiving 5 7 points of evaluation on average (Giorgashvili, 2020, 2021). Table 4 presents factors calculated for the category of Doctor and IT. Each factorial characteristic is presented with its mean evaluation, estimated on the basis of 11 point scale, from the comprising parameters loaded in the factor on the level of 0.5 and more.

Received data gave us sufficient information to shape visual experimental materials-photos-for each category and also, to develop special scales for measuring impressions formed under different experimental conditions.

\section{Experimental Study}

The aim of our experiment was to explore effect of the order of provided information on the mode of social information processing. By varying stereotypic and individuating information about one and the same target into five different order conditions, we aim to measure changes in observer's first impression about the observed target. We assume that the information being provided first, will have a dominant effect on the impression of the target. The dominance will be revealed in the process of inhibition of the associations not related to the information presented on the first place and in excitation of the associations that are related to the information presented on the first place. The inhibition of the 
Table 4. Factors, representing stereotypic and individuating characteristics of doctor and IT.

\begin{tabular}{|c|c|c|c|}
\hline \multicolumn{2}{|l|}{ Stereotypic Characteristics } & \multicolumn{2}{|l|}{ Individuating Characteristics } \\
\hline & $\begin{array}{c}\text { Mean } \\
\text { value }\end{array}$ & & $\begin{array}{c}\text { Mean } \\
\text { value }\end{array}$ \\
\hline \multicolumn{4}{|c|}{ Male Doctor } \\
\hline His age is $36-50$ years & 10 & Is sensitive & 3 \\
\hline Is interested in biology/botany & 10 & Loves computer games & 3 \\
\hline Assumes main financial role in the family & 10 & Is dependent on family & 4 \\
\hline Washes his hands systematically & 10 & Is rebellious type of person, according to clothing & 4 \\
\hline Educated person, who thinks analytically & 10 & style and behavior & \\
\hline Has no free time & 9 & Plays aggressive sports (paintball, box, karate) & 4 \\
\hline Loves to drink and attend parties (traditional feasts) & 8 & Uses narcotics & 4 \\
\hline Is leader & 8 & & \\
\hline \multicolumn{4}{|c|}{ Male IT } \\
\hline His age is $21-23$ years & 10 & Loves to knit or saw & 3 \\
\hline Has new computers/gadgets & 10 & Is sentimental person (who appreciates beauty and & 4 \\
\hline Is active in social network & 10 & likes flowers, violin and beautiful style of sport such & \\
\hline Is very busy & 9 & as ice skiing) & \\
\hline Wears sport style clothing/shoes & 9 & Knows Japanese & 4 \\
\hline Knows electronics & 9 & & \\
\hline Focused on creating new things or find new information & 9 & & \\
\hline
\end{tabular}

associative characteristics will be seen in a low evaluation of associations (characteristics), based on the 11 point evaluative scale. Excitation, in turn, will be revealed by higher evaluations on 11 point scale. Thus, information presented first will show its leading effect on the impression by exciting its associative characteristics and constraining others.

Basing on the experimental procedure and impression measurement scale, we assume that in the condition were stereotypic information is presented first Doctor will be seen through the lens of stereotype, therefore in his evaluations stereotypic associations will receive higher level of excitation, while the associative characteristics related to perceived individuating information will be more inhibited. The same will happen with the impression received from IT.

Contrary to this, in the condition were order of information is reversed, stereotypic characteristics will receive lower points on the scale, than individuating characteristics. Eventually, Doctor will be evaluated based on observed behavior. Associative characteristics related to perceived individuating information will get excited receiving higher evaluations on 11 point scale, than stereotypic associative characteristics, which will be constrained by the observed behavioral information. The same will happen with IT impressions.

As about the mixed condition, impression will be based on both types of information, as both will be integrated into the formed first impression. This will result in averaged evaluations of any associative characteristics. The meaning of average evaluations, will be estimated from the evaluations of given characteristic received in stereotype primacy and behavior primacy conditions. 


\section{Method}

Materials. Material that was used in the experimental study are photos, content of which were shaped on the basis of received stereotypic and individualistic information from preliminary studies. Photos were created in Photoshop program.

Photos of Male IT, Doctor were created by following principles:

- Three photos were created for each category-stereotypic photo, individuating photo and mixed information photo. Totally 6 photos were shaped. The face of the target person depicted on the photo was blurred in every photo. Basing on a preliminary qualitative sturdy (focus groups and survey with open ended questions), the sex of the typical image depicted on the photos was chosen male for both categories.

- Stereotypic photo aims to activate clear stereotypic information about the target depicted on the photo, therefore all of the information depicted on the photo regarding target's appearance, behavior, background and general situation is consistent to category's stereotypic characteristics.

- Individuating photo aims to activate clear behavioral information which is counter stereotypic to an observed category. On this photo main focus is done on a clear depiction of a behavior and the trait lying behind the behavior. As about targets appearance and background information it is held neutral. In some cases, though, background is used as additional information to intensify the meaning of target's counter stereotypic behavior. In addition, in individuating photo in order to depict unequivocal behavioral information, we chose two behavioral instances of chosen individuating characteristic (one behavior as the main behavior and the other as additional one).

- Mixed information photo presents both stereotypic and individuating information together within one photo. In a given photo visual cues of stereotypic photo are mixed with the cues from individuating photo. Eventually, this mixture is depicted in a meaningful social situation. The aim of the photo is to activate both information simultaneously in observer's mind.

- When choosing pertinent information for the photos, we were oriented to choose those stereotypic and individuating characteristics that would be relatively easy to depict visually. Basing on a factorial analysis and factor's mean evaluations, factors which received 8 - 11 points as average were depicted in the stereotypic photo of the category. As about those factorial characteristics which received 1 - 4 points, they were depicted in the individuating photo. Information for photos was also selected from the qualitative descriptions obtained from focus groups and open ended questionnaires.

Final scenarios for the photos of Doctor and IT were based on categories' stereotypical and individuating characteristics given in Table 5 .

By the help of pilot studies and evaluations from trained experts photos had finally shaped in the form they are given in Figure 1 .

Procedure. Experiment for the Doctor and for the IT was held separately. 
Table 5. Stereotypic and individuating scenarios used in the photos of doctor and IT.

\begin{tabular}{|c|c|c|c|}
\hline & Stereotypic Information & Individuating Information & Mixed Information \\
\hline & $\begin{array}{l}36 \text { - } 50 \text { years old male person } \\
\text { Doctor Uniform } \\
\text { Medical accessories } \\
\text { Sits in his office, with different things } \\
\text { related to medicine } \\
\text { He is talking with the patient }\end{array}$ & $\begin{array}{l}\text { Individuating characteristics: } \\
\text { a) playing computer game } \\
\text { b) Being in the mess } \\
\text { Same male person, in mundane clothing } \\
\text { Playing on the computer, in the room, } \\
\text { which is in mess }\end{array}$ & $\begin{array}{l}\text { Same male person, sitting in the messy } \\
\text { medical room, with same medical } \\
\text { accessories and uniform. He is playing } \\
\text { on the computer, screen of which } \\
\text { depicts the same game from } \\
\text { individuating photo }\end{array}$ \\
\hline-1 & $\begin{array}{l}\text { Male person of } 21 \text { - } 5 \text { age } \\
\text { Clothed in jeans and mundane skirt } \\
\text { Sits in the office, full of computer } \\
\text { equipment. Working on the processor, } \\
\text { which is dismantled into small } \\
\text { technical pieces } \\
\text { He's table is in mess }\end{array}$ & $\begin{array}{l}\text { Individuating characteristic: } \\
\text { Sensitive person who likes } \\
\text { a) classic music and ballet } \\
\text { b) flowers } \\
\text { The same male person, with the } \\
\text { mundane clothing, who is sitting in the } \\
\text { room and is listening and watching opera }\end{array}$ & $\begin{array}{l}\text { Same male person who is sitting in the } \\
\text { office, being busy with computer } \\
\text { gadgets, also having messy table full of } \\
\text { technical details, but in the same time } \\
\text { listening to opera, from computer } \\
\text { screen; Also holding flower pot in the } \\
\text { room }\end{array}$ \\
\hline
\end{tabular}

\section{Doctor}

Stereotypic photo

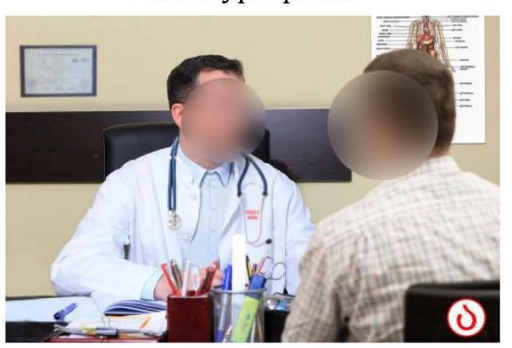

Individuating photo

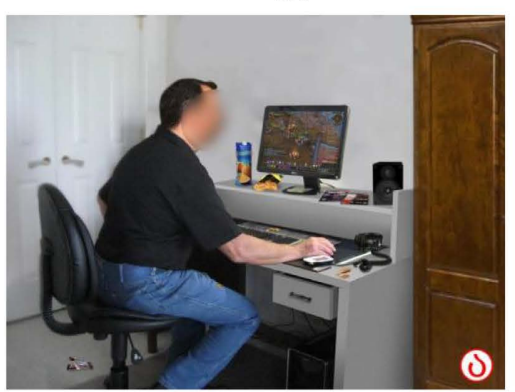

Mixed photo

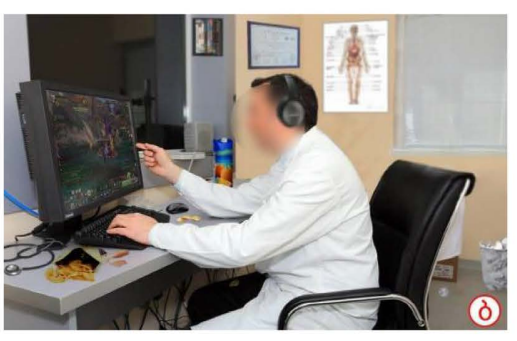

IT

Stereotypic photo

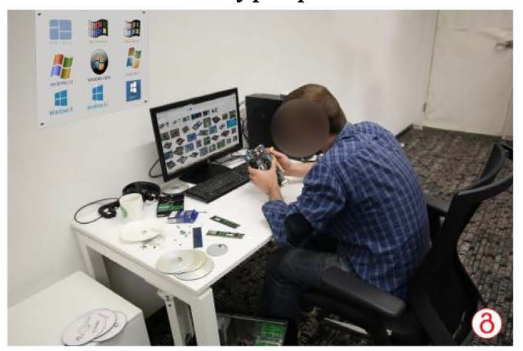

Individuating photo

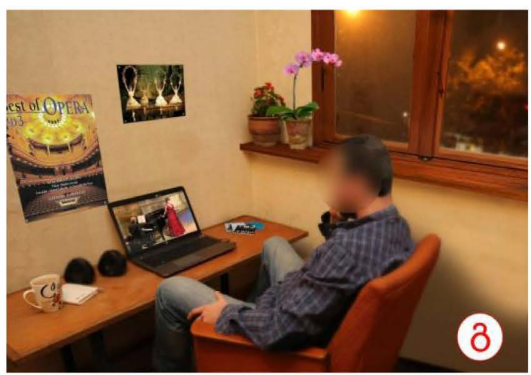

Mixed photo

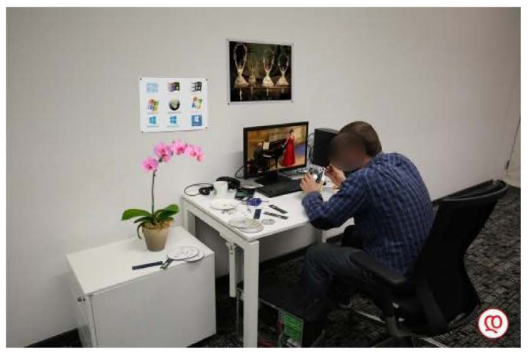

Figure 1. Experimental photos of doctor and IT

Stereotypic and individuating information about the target of Doctor (and IT) was provided via photos into five different order conditions: condition N1-ste- 
reotypic condition, providing only stereotypic information (photo), condition $\mathrm{N} 5$-individuating information condition, providing only individuating information, condition N3-mixed condition, providing both information simultaneously into one photo, condition N2-stereotypic information primacy, providing stereotypic information first and after individuating information, condition N4-individuating information primacy, providing individuating information first and then providing stereotypic one. In the conditions N1, N5 and N3, due to presenting only one photo, procedure took only 10 minutes on average, but conditions N2 and N4 with two photos took 20 minute on average.

Instructions: Participants were instructed that the research was related to the study of associative thinking patterns. After presenting the photo, they were asked to generate any association (ideas) which came to their mind about observed target. Then they were asked to evaluate perceived target from the photo by the scale of associative characteristics. Even though we asked verbally generated responses too, related to the target, these verbal responses were not measured. Impressions were measured by the scale of associative characteristics, in which participant had to evaluate the target according to different stereotypic and individuating associative characteristics.

Regarding the instruction, it is important to note, that in experimental conditions of $\mathrm{N} 2$ and $\mathrm{N} 4$ with two photos presented, participants evaluated the target with the scale only after observing both photos. Here too, however, before providing evaluations with the scale, participants were also asked to give verbal responses after perceiving each photos (what do you think about the person given on the photo). By this procedure we tried to be sure that the participant indeed processed perceived information from each photo actively. In experimental conditions of $\mathrm{N} 2$ and $\mathrm{N} 4$ it was also important that the participants would correctly identify the sameness of the target depicted on two different photos. As the targets' faces were not seen on the photos and as content of the photos was different, it would be uneasy for the participants to identify them correctly. For the reason, we added certain cues on the photos that helped participant to identify target correctly. These cues were initials of the target's name (written in Georgian language), put at the right low angle of the photo (the same initial was an indicator of the same target/person).

Presentation Time: Photos were presented by the computer with software of Power Point, on the screen size of $27 \mathrm{sm}$. The pilot study had revealed the average time for photo presentation-time, which participants needed between observation and response. 45 seconds were set for the presentation of stereotypic photo, 45 seconds for individuating photo and 55 seconds for the mixed one. Given time also comprises the time (15 seconds) assigned for the propositions that lead the participants' perception when observing presented photo.

Propositions: Special propositions, which lead participant's perception of the photo were created for the each photo. These propositions were short sentences, verbally depicting stereotypic and/or behavioral information conveyed on the photo. Some of the propositions were given in terms of readymade interpreta- 
tions of the photo content, but some were given in terms of mere factual information given in the photo. The pertinent set of propositions was presented to the participant simultaneously with the provided photo. Before starting generating verbal or scale evaluations about the target, participant was asked to evaluate each proposition looking at the photo using 11 point scale.

These procedure prompted each participant to pay attention to those visual cues that represented important information put in the photo. As the propositions were given in terms of readymade interpretations, they also prompted participants to interpret the plot of the photo the way it was supposed to be interpreted. And finally, propositions helped to see if the photo indeed activated the type of stereotypic or individuating representations, we were aimed at.

Distracter Task: In order to create the effect of order, in the experimental conditions with two photos, we used a time interval between presentations of the two photos. After presenting the first photo, computer screen moved to a blank page, during which participants were asked to fulfill one task related to colors-they were given colors with the codes and were asked to choose those colors, which they would use for several different reasons. The task took 15 minutes in sum.

After distracter task, before proceeding with the second photo, participants were asked memory related question-if they remembered the first photo and the initials of the name on it. The aim of the question was to remind participant main experimental material after distracter task.

Participants and sample. 144 Georgian students (95 female, 49 male) in Tbilisi State University participated in the experiment conducted on the category of Doctor, the same amount of participants were enrolled in the experiment conducted for the category of IT. All participants provided informed consent at the beginning of the study and read the information on voluntary participation and confidentiality. Participants were selected on basis of convenient sampling; as experimental material was content specific and was adapted to Georgian social stereotypes, those participant, who were living abroad recently and did not share native Georgian representations for IT and Doctor, were aliminatied from the participantion of the study. After selection each participant was randomly assigned to either of the experimental group. Each experimental condition enrolled 27 - 30 participants, whose age was 20 on average and who had lived in Georgia for at least three years for the time experiment being held.

Measurement. In order to measure received impressions in different order conditions we administered two scales, one to measure impressions received for category of Doctor and the other to measure impression of IT. By the associative characteristics given in the scale of Doctor or IT participants were asked to evaluate observed target according to the degree he holds these characteristics. Each scale enrolled associative characteristics related to the stereotype of the category and associative characteristics related to the individuating behavior of the category portrayed on the photo. Final impression was determined according to the degree of activation and inhibition of either type of associative characteristics 
measured on 11 point scale ( +5 most typical, -5 least typical).

In order to measure impressions about Doctor, final scale enrolled 26 stereotypic associations to measure activation of stereotype and seven individuating associations to measure activation of representation related to individuating information. Stereotypic associations for the measurement scale of Doctor had been chosen from factorial analysis conducted for Doctor (data received from preliminary quantitative survey). For this reason we selected those factors which received 8 - 11 points as average, although from initially selected 31 stereotypic factors, pilot study lead us to discard five of them. Two factorial characteristics were discarded for being evaluated similarly in both, stereotypic and individuating photos, the others for being activated in not relevant photo. In order to measure impressions about IT, final scale enrolled 10 stereotypic and eight individuating associations. In this case, basing on the pilot study, only two stereotypic characteristics were dismissed from the scale. For stereotypic characteristics finally enrolled in the scale of Doctor and IT, see Table 6.

For individuating characteristics that were enrolled in the scale to measure mental associations related to observed behavioral information of Doctor we selected those individuating associations that were revealed by additional pilot study. Based on the qualitative and hierarchical cluster analysis, we selected those associative characteristics which were mentioned frequently-at least $15 \%$ of the responses. Eventually, seven associative characteristics had been selected related to the individuating behavior of Doctor and 10 for the individuating behavior of IT (see Table 7). Revealed individuating associations were all enrolled

Table 6. Stereotypic associations of doctor and IT enrolled in measurement scales.

\begin{tabular}{|c|c|}
\hline \multicolumn{2}{|c|}{ Stereotype of Doctor } \\
\hline He supports family financially & He is kind \\
\hline He may be engaged in academic sphere & $\mathrm{He}$ is the petty one \\
\hline Likes to go outdoors & He is a family man \\
\hline Proceeds profession of his father & He is proud person \\
\hline Wants to work in politics & He is interested in biology and/or botany \\
\hline He is clever and intellectual & Has intelligent friends \\
\hline He has a sense of humor & He is warm and loving person \\
\hline He is leader & Visits theatres \\
\hline He washes his hands systematically & He is educated \\
\hline He is strict & Likes to demonstrate his power \\
\hline He is gentlemen & Uses his hands skillfully \\
\hline He is successful person & He is professional \\
\hline He understands technical subjects & He is oriented on new ideas/development \\
\hline \multicolumn{2}{|c|}{ Stereotype of IT } \\
\hline He is professional & Is engaged in a social web actively \\
\hline He is educated & He is oriented on a new ideas/development \\
\hline He spends his whole time with computer & He want to earn lots of money \\
\hline He is gentlemen with the women & He is oriented at having modern computers/ \\
\hline He does not like to be ordered & gadgets and accessories \\
\hline He understands technical subjects & \\
\hline
\end{tabular}


Table 7. Associations related to the individuating information of categories.

\section{Doctor}

Man who is Playing Computer games, while Sitting in Disorganized Room

\begin{tabular}{lc}
\hline Disordered (unorganized, not stable, forgets everything) & $50.0 \%$ \\
Irresponsible & $40.6 \%$ \\
Unclean (not taking care of himself) & $47.9 \%$ \\
Lazy (unemployed) & $31.3 \%$ \\
Does not have aim (interests) in life & $31.3 \%$ \\
Immature & $21.9 \%$ \\
Not communicable & $18.8 \%$ \\
\hline \multicolumn{1}{c}{ Man who is Listening to Classic Music and Has a Flower in } & the Room \\
\hline Sensitive & $52.9 \%$ \\
Cultural (gentlemen) & $41.2 \%$ \\
Intellectual person, with education & $35.3 \%$ \\
He is peaceful, not impulsive & $35.3 \%$ \\
Creative person, related to art & $38.2 \%$ \\
Caring, attentive & $35.3 \%$ \\
Organized (in every way) & $32.4 \%$ \\
Warm, friendly person & $17.6 \%$ \\
Loves beauty & $14.7 \%$ \\
\hline
\end{tabular}

in the final scale of Doctor and IT, to measure activation of mental representations coming from observed behavior of the Doctor or IT.

\section{Results}

\subsection{Analysis of the Impressions for the Category of Doctor}

According to the mean evaluation received for the propositions related to the photos of Doctor, it is seen that photos indeed activated the information they were required to activate (see Table 8).

We conducted cross tabulation analysis to see if evaluations of typicality of Doctor followed effect of order. For this reason, evaluations of typicality from 11 point scale were transformed to categorical evaluations-"is typical" and "in not typical" Doctor. Analysis showed that in different experimental conditions, the doctor is not always evaluated as a typical representative of the category. The difference between evaluations is statistically significant $\mathrm{X}^{2}=303.306, \mathrm{df}(4), p=$ $0.000<0.05$ and it follows effect of primacy. In particular, in N2 and N4 order conditions stereotypic evaluations are dominant, but with the change of the order of presentation this dominance diminishes-in the condition where stereotypic information is presented first Doctor is evaluated as more typical Doctor (84\%), than in the condition when the same information is presented later 
Table 8. Mean Evaluation of propositions for the photos of doctor.

\begin{tabular}{lcc}
\hline \multirow{2}{*}{ Propositions } & Stereotypic Photo & Individuating Photo \\
\cline { 2 - 3 } & \multicolumn{2}{c}{ Mean evaluations } \\
\hline He is a typical doctor & 10.30 & 1.81 \\
He loves to play computer games & 10.06 \\
He sits in disorganized room & 8.53 \\
\hline
\end{tabular}

(72\%). In the same way, in individuating information primacy condition Doctor is evaluated as more not typical (28\%), than when the same individuating information is presented second (16\%). Thus, the primacy effect changes the influence of each type of information on the impression. This is especially seen in diminished impact of stereotypic information (see Table 9).

According to factorial analysis and linear regression, two factors out of three significantly predict the judgment about typicality of Doctor. On the level of $p<$ 0.05 linear regression model has been significant $\mathrm{F}(3,138)=49.660, p=0.000<$ $0.05, \mathrm{R}=0.72$. The typicality of Doctor depends on two characteristics: successful and educated personality, according to which the typicality of the doctor equals to $6.939+2.102(\mathrm{~B}=2.102)$ and immature and disorganized personality..., where the judgment on typicality equals to $6.939+1.794(\mathrm{~B}=1.794)$. Following characteristics significantly predict the typicality of Doctor: successful and educated person $\mathrm{B}=2.102$, Beta $=0.55, \mathrm{t}=9.33, p<0.000$ and immature and disorganized personality... $\mathrm{B}=1.794$, Beta $=0.47, \mathrm{t}=7.87, p<0.000$, as about third factor-cultural and intellectual personality-it did not show any significance $\mathrm{B}=0.140$, Beta $=0.04, \mathrm{t}=0.62, p=0.54$ (see Table 10 ).

Comparing impressions received in five experimental conditions, each factor showed statistically significant difference on the level of $p<0.05$ : successful and educated person $\mathrm{F}(4,571)=87.01, p=0.000<0.05, \eta_{p}^{2}=0.38$, cultural and intellectual personality $\mathrm{F}(4,571)=57.48, p=0.000<0.05, \eta_{p}^{2}=0.20$ and immature and disorganized personality $\mathrm{F}(4,571)=57.48, p=0.000<0.05, \quad \eta_{p}^{2}=$ 0.29. According to data Doctor is indeed evaluated according to the information provided on the first place. In the conditions providing only stereotypic information (N1) or stereotypic information at first place (N2) Doctor's stereotypic characteristics (successful and educated person and cultural and intellectual personality) became exited on a higher level, while the same characteristics got inhibited in conditions of individuating information provided solely or in the first place. The same can be said about individuating characteristic (immature and disorganized personality) which was inhibited in stereotypic conditions, but exited in the conditions of individuating information (see Table 11).

By comparing impressions received in order conditions (N2 and N4) only one factor showed statistically significant difference between the evaluations of Doctor. This factor is immature and disorganized personality... $\mathrm{t}(206)=2.14$, $p=0.03<0.05$, which is individualistic characteristic and comes from observed individuating information. Evaluation of Doctor according to this characteristic 
Table 9. Cross tabulation analysis of typicality across experimental conditions for doctor.

\begin{tabular}{|c|c|c|c|c|c|c|c|}
\hline & & \multicolumn{5}{|c|}{ Experimental Conditions } & \multirow[b]{2}{*}{ Total } \\
\hline & & N1 & $\mathrm{N} 2$ & N3 & N4 & N5 & \\
\hline $1-6$ points & 1-not typical & $3.3 \%$ & $16.0 \%$ & $63.3 \%$ & $28.0 \%$ & $100 \%$ & $44.4 \%$ \\
\hline $7-11$ points & 2-typical & $96.7 \%$ & $84.0 \%$ & $36.7 \%$ & $72.0 \%$ & & $55.6 \%$ \\
\hline
\end{tabular}

Table 10. Regression analysis for the three factors describing doctor.

\begin{tabular}{lccccc}
\hline \multicolumn{1}{c}{ Factors } & B & SE B & $\beta$ & t & $p$ \\
\hline Successful and educated person & 2.102 & 0.225 & 0.551 & 9.332 & 0.000 \\
Immature and disorganized personality & 1.794 & 0.228 & 0.465 & 7.872 & 0.000 \\
Cultural and intellectual personality & 0.140 & 0.225 & 0.037 & 0.622 & 0.535 \\
\hline
\end{tabular}

Table 11. Evaluations of doctor across five experimental condition.

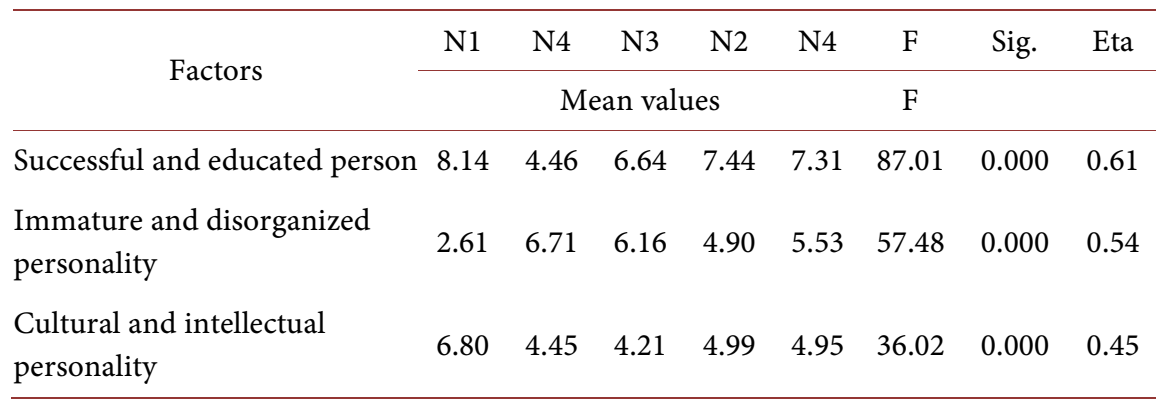

${ }^{\star} p<0.05$.

follows the effect of primacy; in particular Doctor is evaluated as more immature and disorganized person in the conditions when individuating information is presented first $(M=5.53)$, than in the conditions where stereotypic information is presented first-in this last case, he seems to be a less immature and disorganized person $(M=4.90)$. This results show, that individuating association become excited on a higher level, when pertinent individuating information was provided first, than when it was provided second. Contrary to this, when the same individuating information was provided later, given individuating association revealed higher level of inhibition (see Table 12).

As about results of mixed condition evaluations did not averaged as we expected. Comparing impressions of mixed condition (N3) with different order conditions (N2 and N3) all three factors-successful and educated person $\mathrm{F}(2$, $325)=3.37, p=0.03<0.05, \eta_{p}^{2}=0.14$, immature and disorganized $\mathrm{F}(2,325)=$ 8.58, $p=0.000<0.05, \eta_{p}^{2}=0.50$ and cultural and intellectual personality $\mathrm{F}(2$, $325)=3.90, p=0.02<0.05, \eta_{p}^{2}=0.23$-were evaluated in a significantly different way.

By averaging, we anticipated to receive evaluations which were the exact average of the two evaluations received on the given factor in conditions N2 and $\mathrm{N} 4$, instead we received polarized evaluations towards individuating information. 
Table 12. Evaluation of doctor according to three factors in different order conditions.

\begin{tabular}{lcccc}
\hline \multirow{2}{*}{ Factors } & \multicolumn{3}{c}{ Mean } & \\
\cline { 2 - 5 } & $\mathrm{N} 2$ & $\mathrm{~N} 4$ & $\mathrm{t}$ & Sig. \\
\hline Successful and educated person & 7.44 & 7.31 & 0.777 & 0.438 \\
Immature and disorganized personality & 4.90 & 5.53 & 2.149 & 0.033 \\
Cultural and intellectual personality & 4.99 & 4.95 & -0.776 & 0.438 \\
\hline
\end{tabular}

${ }^{*} p<0.05$.

The Doctor was evaluated as more immature and disorganized person $(M=6.16)$ and less cultural and intellectual $(\mathrm{M}=4.21)$ and also less successful and educated $(\mathrm{M}=4.99)$, than it was in stereotypic condition (successful $\mathrm{M}=7.44$, Immature $M=4.90$, cultural $M=4.99$ ). These evaluations are close to the evaluations received under the primacy of individuating information $(\mathrm{M}=7.31, \mathrm{M}=5.53, \mathrm{M}=$ 4.95), but surprisingly in the mixed conditions evaluations become more extreme than in individuating one.

\subsection{Analysis of the Impressions for the Category of IT}

Concerning evaluations of IT, here too photos activated required interpretations as photo propositions were evaluated as it was expected (see Table 13).

In the case of IT cross tabulation analysis was also conducted. After transforming evaluations of typicality from 11 point scale to categorical one, analysis revealed that IT wasn't evaluated as a typical representative across five experimental conditions (see Table 14). The difference between evaluations is statistically significant $\mathrm{X}^{2}=315.290 \mathrm{df}(4), p=0.000<0.05$. However, if we look closer at the evaluations of typicality received in order conditions (N2 and N4) we see, that there is not much difference between them. The addition of stereotypic information to the individuating one (or vice versa) does not lead to any significant changes in impressions about typicality of the IT. So far, cross tabulation analysis does not reveal primacy effect.

According to factor analysis and linear regression, out of three differentiated factors, two factors significantly predicted judgments about the typicality of the IT. On the level of $p<0.05$ model of linear regression was significant $\mathrm{F}(3,200)=$ $4.82, p<0.003<0.05, \mathrm{R}=0.16$. The typicality of the doctor depended on two characteristics-professional, who is engrossed in his work and is oriented toward development, according to which typically equals to $3.227+0.490(\mathrm{~B}=0.490)$ and he is a gentleman where the judgment on typicality equals to $3.227+0.509$ $(\mathrm{B}=0.509)$. These characteristics significantly predict the typicality of IT: professional, who is engrossed in his work and is oriented toward development $\mathrm{B}=$ 0.490, Beta $=0.110, \mathrm{t}=2.63, p<0.009$, gentleman $\mathrm{B}=0.509$, Beta $=0.114, \mathrm{t}=$ $0.73, p<0.007$; as about the third factor, it did not predict significant effect $\mathrm{B}=$ 0.054 , Beta $=0.01, \mathrm{t}=0.29, p=0.77>0.05$ (see Table 15).

By comparing five experimental conditions each factor revealed statistical significance on the level of $p<0.05$ : professional, engrossed in his work and oriented 
Table 13. Evaluation of propositions for the photos of IT.

\begin{tabular}{lcc}
\hline \multirow{2}{*}{ Propositions } & Stereotypic Photo & Individuating Photo \\
\cline { 2 - 3 } & \multicolumn{2}{c}{ Mean values } \\
\hline He is a typical IT & 9.59 & 3.07 \\
He is sitting in a disorganized room & 5.97 & \\
He loves opera/ballet & & 9.97 \\
He loves flowers & 6.87 \\
\hline
\end{tabular}

Table 14. Cross tabulation analysis of typicality across experimental conditions for IT.

\begin{tabular}{|c|c|c|c|c|c|c|c|}
\hline & & \multicolumn{5}{|c|}{ Experimental Conditions } & \multirow[b]{2}{*}{ Total } \\
\hline & & N1 & $\mathrm{N} 2$ & N3 & N4 & N5 & \\
\hline $1-6$ points & 1-not typical & $12.5 \%$ & $12.0 \%$ & $23.3 \%$ & $11.5 \%$ & $100 \%$ & $32.9 \%$ \\
\hline $7-11$ points & 2-typical & $87.5 \%$ & $88.0 \%$ & $76.7 \%$ & $88.5 \%$ & & $67.1 \%$ \\
\hline
\end{tabular}

Table 15. Regression analysis for the three factors describing IT.

\begin{tabular}{lccccc}
\hline \multicolumn{1}{c}{ Factors } & B & SE B & $\beta$ & t & $p$ \\
$\begin{array}{lcccc}\text { Professional, who is engrossed in his } \\
\text { work and is oriented toward development }\end{array}$ & 0.490 & 0.187 & 0.110 & 2.630 & 0.009 \\
$\begin{array}{l}\text { Warm and cultural person } \\
\text { Gentleman }\end{array}$ & 0.054 & 0.187 & 0.012 & 0.292 & 0.770 \\
\hline
\end{tabular}

${ }^{\star} p<0.05$.

on development $\mathrm{F}(4,559)=63.840, p<0.000<0.05, \eta_{p}^{2}=0.31$, Gentleman $\mathrm{F}(4,559)=7.718, p<0.000<0.05, \eta_{p}^{2}=0.28$, warm and cultural person $\mathrm{F}(4$, $559)=53.670, p<0.000<0.05, \eta_{p}^{2}=0.05$ (see Table 16). From received evaluation it is seen that two characteristics indeed follow the effect of primacy-stereotypic characteristic-professional, engrossed in his work and oriented on development-become excite more in stereotypic information condition (stereotype information provided solely (N1) or at first (N2)), than in individuating one $(\mathrm{N} 5, \mathrm{~N} 4)$. In the same way one of the individuating characteristics-Gentleman received higher level of excitation when pertinent individuating information was provide solely or at first. The same characteristic become more inhibited in stereotypic conditions. Surprisingly, the same dynamic was not observed for the other individuating characteristic, which is Warm and Cultural Person. This characteristic revealed contradictory effect and instead of being excited by pertinent individuating information (N5), it become excited by stereotypic one (N1). This effect may be indicate towards the nature of the IT's stereotypic photo, which may represent the image of not a standard IT person, but an image of a cultural IT person.

Comparing two experimental conditions related to different orders of information (N2, N4), two factors showed statistically significant difference. These 
factors are-gentleman $\mathrm{t}(197.535)=3.88, p<0.000<0.05$ (individuating factor) and professional, who is engrossed in his work... $\mathrm{t}(202)=-4.050, p<0.000<$ 0.05 (stereotypic factor). The third factor warm and cultural person (individuating factor) did not show significant effect on the impression $\mathrm{t}(202)=1.74, p=$ $0.083>0.05$ (see Table 16).

In these conditions, results show that the evaluation of the IT follows the effect of primacy. In particular, IT was evaluated as being more professional $(\mathrm{M}=$ $7.81)$ and less gentleman $(M=6.20)$ in the condition with stereotypic information being presented first, then in the condition with individuating information provided first. In this last condition, the same IT was evaluated as less professional $(M=7.26)$ and more gentleman $(M=6.81)$, than it was in the condition N2, with stereotypic information on the first place. Thus, here too, when pertinent stereotypic information was provided first, the stereotypic characteristic got excited on a higher level and individuating characteristic become inhibited more, than when this information was provided second. Contrary processes have taken place in reversed order condition (see Table 17).

For the mixed condition, the same two factors showed statistically significant difference between impressions received in three conditions- N3, N4 and N5. In particular, characteristics being a professional, who is engrossed in his work $\mathrm{F}(2$, $313)=11.71, p<0.000<0.05, \eta_{p}^{2}=0.07$ and being a gentleman $\mathrm{F}(2,313)=$ 9.51, $p<0.000<0.05, \eta_{p}^{2}=0.02$ are the factors that significantly affected the evaluation of the IT in given three conditions. As about the third one-warm and cultural person-it was still not significant $\mathrm{F}(2,313)=2.31, p=0.1>0.05, \eta_{p}^{2}$ $=0.06$. In mixed condition, basing on the evaluation of statistically significant

Table 16. Evaluations of IT across five experimental condition.

\begin{tabular}{lccccccccc}
\hline \multirow{1}{*}{ Factors } & $\mathrm{N} 1$ & $\mathrm{~N} 5$ & $\mathrm{~N} 3$ & $\mathrm{~N} 2$ & $\mathrm{~N} 4$ & $\mathrm{~F}$ & Sig. & Eta \\
\cline { 2 - 9 } & \multicolumn{7}{c}{ Mean values } \\
\hline $\begin{array}{l}\text { Professional, engrossed in his work } \\
\text { and oriented on development }\end{array}$ & 8.23 & 5.46 & 8.02 & 7.81 & 7.26 & 63.84 & 0.000 & 0.56 \\
$\begin{array}{l}\text { Warm and cultural person } \\
\text { Gentleman }\end{array}$ & 8.47 & 6.87 & 7.42 & 7.24 & 7.24 & 53.67 & 0.000 & 0.53 \\
\hline
\end{tabular}

${ }^{*} p<0.05$.

Table 17. Evaluation of IT according to three factors in different order conditions.

\begin{tabular}{|c|c|c|c|c|}
\hline \multirow{2}{*}{ Factors } & \multicolumn{2}{|c|}{ Mean } & \multirow[b]{2}{*}{$\mathrm{t}$} & \multirow[b]{2}{*}{ Sig. } \\
\hline & $\mathrm{N} 2$ & $\mathrm{~N} 4$ & & \\
\hline $\begin{array}{l}\text { Professional, engrossed in his work and oriented } \\
\text { on development }\end{array}$ & 7.81 & 7.26 & 3.869 & 0.000 \\
\hline Warm and cultural person & 7.24 & 7.24 & 1.730 & 0.08 \\
\hline Gentleman & 6.20 & 6.81 & -4.09 & 0.000 \\
\hline
\end{tabular}


characteristics, impression did not averaged in the case of IT too. Although, contrary to the results of Doctor, instead of leaning towards individuating information, IT impressions become polarized towards the stereotypic information. In particular, IT was evaluated as more professional $(\mathrm{M}=8.02)$ and less gentlemen $(M=6.23)$, than it was in individuating primacy conditions (professional $M=7.26$; gentlemen $M=6.81$ ) and especially, in stereotypic primacy condition $(\mathrm{M}=7.81 ; \mathrm{M}=6.20)$.

\section{Conclusion}

Results received from the comparison of order conditions show that information which is provided first influences impression more than the information provided later. The effect of primacy is clearly seen from the evaluations of both categories, IT and Doctor. In both cases, the target was seen through the lenses of firstly provided information. In particular, in the condition where stereotypic information was provided first Doctor and IT were perceived through the lenses of stereotype, therefore Doctor was evaluated as a less immature and disorganized person and IT as being a stronger professional, oriented on development and less gentleman. In the condition where individuating information was provided first Doctor and IT were evaluated based on the perceived behavioral information, rather than on the stereotypic image-Doctor was evaluated as a more immature and disorganized person (then this happened in the conditions with the stereotypic information first) and IT as being less professional/not so much oriented toward development, but more gentleman. Proceeding from the results, primacy effect has revealed itself in excitation of associative characteristics, related to firstly provide information and in inhibitions of those associative characteristics, which were related to other information. In case of Doctor and IT is clearly seen, that firstly provided stereotypic information activated stereotypic characteristics on a higher level, while inhibited individuating associations. In the same way, firstly provided individuating behavior, activated pertinent associations, but inhibited stereotypic one.

Thus our hypothesis about the primacy effect on impression has been confirmed, as in different order conditions targets have been evaluated differently and the difference was dominantly led by the interpretation coming from the firstly provided information. Besides this, the cognitive mechanism of the associative network and processes occurring in it (such as inhibitions and excitation), indeed helped to measure the dominance of the either information in social information processing. Although the dominance has revealed itself in a small difference between evaluations received in different order conditions (N2 and N4), it still appears to be statistically significant (on the level of $p<0.5$ ).

\section{Discussion and Future Directions}

Given study shows that stereotypic informant is not a dominant type of processing, but it is mediated by the factor of order. The stereotypic processing can lead the 
impression in case relevant stereotypic information is presented first, though in the same manner, if the individuating information is presented first, then impression will be dominated by the perceived behavior. These results concerning the order of the information presentation are in accord with Asch's (1946) empirical study, in which adjectives with positive and negative meaning presented in a different order, resulted in different evaluations, depending on the adjectives presented on the first two places. In our case too, firstly provided information influenced the interpretation of other information provided after it.

The effect of the primacy and order can be explained by the parallel constrain theory itself. The cognitive network of associations and simultaneous processes through which concepts mutually change each other's meaning, can explain how hard it is to change the initial judgment (Read, Vamnan, \& Miller, 1997). According to the model, when the initial information is received in the system, by activating its associations, it activates the energy surface of a certain spot given in whole network. The excitation of the energy leads to such condition when constraints between activated associations are satisfied and final judgment is made. At this point, activated energy creates well or valley, which starts to attract all other nodes around it (Read, Vamnan, \& Miller, 1997: p. 36). Thus, for the newly incoming information it seems hard to change the direction of processing, as it cannot excel its constraining effect on the associations, which are already activated. Instead, it gets attracted to that already activated and stabilized spot of the network, which in turn changes (constrains) the meaning of newly incoming information.

In addition, according to same authors parallel connectionist network represents associative connections which are more bidirectional and not linear, therefore processes of activation have sigmoid form $(S)$ and it can take any meaning from -1 to +1 , rather than a discrete meaning such as 0 and 1 (Read, Vamnan, \& Miller, 1997). From this point, our logical assumption about the measurement on $+5-5$ point scale and our data analysis in terms of more/less activation is relevant to the theory.

As about our hypothesis regarding averaging effect of impression is case of simultaneous information presentation, hypothesis was not proved. Instead of averaging, we received seriously polarized impressions in both cases-Doctor was evaluated more stereotypically and IT more individually, than this happened in either of the order conditions ( 22 and N4). The fact that we did not receive impressions with averaged evaluations, can be explained by valence of used stereotypic of individuating information. Unfortunately, we did not control the valence of used information, therefore it revealed its effect in the mixed condition with extreme polarized evaluations. It is known that negative information has more influence over cognitive processes than the positive information. In particular, observers pay more attention to negative information, than to positive. Besides, negative information gets memorized more strongly, than positive information and its effect on judgment is maintained after the week (Richey, Mcclelland, \& Shimkunas, 1967). If we look closely, in the mixed condition for Doctor 
we used individuating information which is regarded as socially undesirable behavior; as about IT we used such individuating information valence of which is strongly positive. By comparing this information to the stereotypic information of IT, it may be reasonable to think that stereotypic information-disorganized room of IT-assumed a negative valence.

Extremity of polarized impression can also be explain from the point of contrast. Even though the same information was presented in order conditions, in the case of the mixed one, because of the simultaneous presentation, the contrast effect has become sharpened. According to Kunda and Thagard (1996) when counter stereotypic information is presented simultaneously, this may result in intermediate evaluations (intermediate to those evaluations when this information is presented alone). But, besides such averaged impressions, authors also refer to polarized evaluations, especially when extremely counter-stereotypic individuating information is presented (Kunda \& Thagard, 1996). The thing that information used in our experiment is extremely counter-stereotypic, is seen in verbal evaluations of the participants and a sense of surprise toward the behavior of Doctor and IT.

The extremity of the evaluations can also be explained hypothetically from the notion of emergent attributes, related to activation of atypical subtype to explain observed contradictory categorical information (Kunda \& Thagard, 1996). Although emergent attributes are measured qualitatively, Hastie and his colleague (1990) measured emergent attribute by the rating scale, in which outside rating or polarized evaluations, were considered as emergence of emergent attributes. If we relate this method to our scale of evaluation, it may be possible to think that extremely polarized evaluations represent the case of emergent attributes and activation of a certain subtype that come from the attempt to explain two very contradictory pieces of information.

Thus, valence and contrast indeed play important roles in information processing that need to be explored further. It is especially interesting to find their relationship toward parallel connectionist model of associative network. As about the study itself, result about primacy needs to be reexamined using another method of measurement, namely the qualitative measurement of verbal responses and also the measurement based on adjectives (inherited and emergent attributes).

\section{Practical Suggestions}

Thus, the study highlights the importance of primacy effect between stereotypic and individuating content. It proves that the dominance of stereotypic thinking indeed can be weakened by the effect of the order. It appears that observer tends to be a more careful thinker when he attends to individuating information about the other person first. Without decent attention to this type of information observer is doomed to label others invalidly. The feeling which spurs from this type of categorical thinking in the observer is "Oh... of course I know who this person is". Precisely, such fast judgments and predictions about other's personal traits, abilities and his future behaviors, cause observer's blindness in realistic 
perception of the other. By categorizing others in such a way we, as an observer, diminish personal value of each person, we lose individuality of the person we interact with and this way make our interpersonal relationship unsatisfactory and void. In the same way, not being realistic and attentive to signals coming from individuating behavior, may tend us to end up with unsafe relationships. Our study gives us deeper insight into the irrationality of our perceptual process and also warns us about the importance of individuating information to be attended to carefully. Only in this way, we'll be able to balance social interaction with others in our lives better. By being more conscious of potential cognitive setbacks, we can become more realistic towards outside social world.

In addition to observer's perspective, study results may also contribute to the domain of impression management. Knowing how to diminish effect of stereotypic thinking about oneself may help elicit desired impressions from others. This is especially important for the cases where stereotypic judgments may lead to negative effects. Having an interview for a new job, asking for help and support, offering relationship to other or merely, interrogating with another person, are those few, but important cases where we need to be perceived adequately. In the face of potential activation of gender, age, professional or other category related stereotypes, making our behavior be attended and/or underlying our individuating characteristics at first place, will tend us to avoid stereotypic projections from others.

Impression management is also important regarding forming common attitudes towards central social and political issues in the society. Of course this can be understood as manipulating people's opinion, which is absolutely unacceptable. However, in life there are also other cases when we really need to make the right decision together as society. Unfortunately, sometimes important aspect of the problem is lost in stereotypic content, and eventually is devaluated. Political parties and nongovernmental organizations should convey information in a way that diminishes stereotypic perception of the issue itself or/and of the actor who is providing this information.

Thus, study indeed has a potential value for us; if handled with responsibility study results may serve us well on both, personal and social levels of life. Although, it should be noted again, that the research of stereotype dominance versus individuation dominance through the lens of order effect need to be continued.

\section{Acknowledgements}

Given research was submitted to the faculty of Psychology and Educational Sciences, at Tbilisi State University, to fulfill requirement for the degree of $\mathrm{PhD}$ in Psychology (thesis defended in 2019). I'd like to thank my supervisor from TSU Prof. Revaz Jorbenadze and a supervisor from ATEI Prof. Aikaterini Sousamidou, for their guidance in the course of the study. Also, I am grateful to Prof. Vano Kechakmadze, for his thoughtful advice on research and support. 


\section{Conflicts of Interest}

The author declares no conflicts of interest regarding the publication of this paper.

\section{References}

Andersen, S. M., \& Klatzky, R. (1987). Traits and Social Stereotypes: Levels of Categorization in Person Perception. Journal of Personality and Social Psychology, 53, 235-246. https://doi.org/10.1037/0022-3514.53.2.235

Asch, S. E. (1946). Forming Impressions of Personality. The Journal of Abnormal and Social Psychology, 41, 258-290. https://doi.org/10.1037/h0055756 https://www.romolocapuano.com/wp-content/uploads/2013/08/Asch-Forming-Impres sions-Of-Personality.pdf

Bargh, J. A. (1989). Conditional Automaticity: Varieties of Automatic Influence in Social Perception and Cognition. In J. S. Uleman, \& J. A. Bargh (Eds.), Unintended Thoughts (pp.3-51). New-York: Guilford Press.

Bargh, J. A., \& Pratto, F. (1986). Individual Construct Accessibility and Perceptual Selection. Journal of Experimental Social Psychology, 22, 293-311. https://doi.org/10.1016/0022-1031(86)90016-8

Baron, R. M., Albright, L., \& Malloy, T. E. (1995). Effects of Behavioral and Social Class Information on Social Judgment. Personality and Social Psychology Bulletin, 21, 308-315. https://doi.org/10.1177/0146167295214001

Beckett, N. E., \& Park, B. (1995). Use of Category versus Individuating Information: Making Base Rate Salient. Personality and Social Psychology Bulletin, 21, 21-31. https://doi.org/10.1177/0146167295211004

Bless, H., Schwarz, N., \& Wieland, R. (1996). Mood and the Impact of Category Membership and Individuating Information. European Journal of Social Psychology, 26, 935-959. https://doi.org/10.1002/(SICI)1099-0992(199611)26:6\%3C935::AID-EJSP798\%3E3.0.C $\underline{\mathrm{O} ; 2-\mathrm{N}}$

Bodenhausen, G. V., \& Lichtenstein, M. (1987). Social Stereotypes and Information Processing Strategies: The Impact of Task Complexity. Journal of Personality and Social Psychology, 52, 871-880. https://doi.org/10.1037/0022-3514.52.5.871

Brink, J. H. (1974). Impression Order Effect as a Function of the Personal Relevance of the object of Description. Memory and Cognition, 2, 561-565.

https://doi.org/10.3758/BF03196921

Casselden, P. A., \& Hampson, S. E. (1990). Forming Impressions from Incongruent Traits. Journal of Personality and Social Psychology, 59, 353-362. https://doi.org/10.1037/0022-3514.59.2.353

Chartard, T. L., Bargh, J. A., \& vanBaaren, R. B. (2006). Linking Automatic Evaluation to Mood and Information Processing Style: Consequences for Experienced Affect, Impression Formation, and Stereotype. Journal of Experimental Psychology, 135, 7-77. https://doi.org/10.1037/0096-3445.135.1.70

Dreben, E. K., Fiske. S. T., \& Hastie, R. (1979). The Independence of Evaluative and Item Information: Impression and Recall Order Effect in Behavior-Based Impression Formation. Journal of Personality and Social Psychology, 37, 1756-1768. https://doi.org/10.1037/0022-3514.37.10.1758

Fiske, S. T., \& Neuberg, S. L. (1990). A Continuum of Impression Formation, from Category-Based to Individuating Processes: Influences of Information and Motivation on Attention and Interpretation. Advances in Experimental Social Psychology, 23, 1-74. 
https://doi.org/10.1016/S0065-2601(08)60317-2

Fiske, S. T., \& Pavelchak, M. A. (1986). Category Based Versus Piecemeal Based Affective Responses: Developments in Schema-Triggered Affect. In R.M. Sorrentino \& E.T. Higgins (Eds.), Handbook of Motivation and Cognition: Foundations of Social Behavior (pp. 167-203). Guilford Press.

Fiske, S. T., Neuberg, S. L., Beattie, A. E., \& Milberg, S. J. (1987). Category Based and Attribute Based Reactions to Others. Some Informational Conditions of Stereotyping and Individuating Processes, 23, 399-427. https://doi.org/10.1016/0022-1031(87)90038-2

Fiske, S.T. (1988). Compare and Contrast: Brewer's Dual Process Model and Fiske et al.'s Continuum Model. In T.K. Srull, \& R. S. Wyer Jr. (Eds.), Advances in Social Cognition: A Dual Process Model of Impression Formation (Vol. 1, pp.65-76). Lawrance Erlbaum Associates.

Gawronski, B., Ehrenberg, K., Banse, B., Zukova, J., \& Klauer, C. (2003). It's in the Mind of the Beholder: The Impact of Stereotypic Associations on Category-Based and Individuating Impression Formation. Journal of Experimental Social Psychology, 39, 16-30. https://doi.org/10.1016/S0022-1031(02)00517-6

Gettleman, G. (2007, December 1). Calls in Sudan for Execution of British Teacher. The New Yourk Times. https://www.nytimes.com/2007/12/01/world/africa/01sudan.html

Giorgashvili, M. (2020). Georgian Stereotypes. Intellectual, 41, 49-57

Giorgashvili, M. (2021). Social Stereotypes and Cognitive Mechanism of their Processing. Georgian Scientists, 3, 3.

Gollin, E. S. (1954). Forming Impressions of Personality. Journal of Personality, 23, 65-76. https://doi.org/10.1111/j.1467-6494.1954.tb02338.x

Hastie, R., Schroeder, C., \& Weber, R. (1990). Creating Complex Social Conjunction Categories from Simple Categories. Bulletin of the Psychonomic Society, 28, 242-247. https://doi.org/10.3758/BF03334016

Kardes, F. R., \& Herr, P. M. (1990). Order Effects in Consumer Judgment, Choice, and Memory: The Role of Initial Processing Goals. Advances in Consumer Research, 17, 541-546.

Kopetz, C., \& Kruglanski, A. W. (2008). Effects of Accessibility and Subjective Relevance on the Use of Piecemeal and Category Information in Impression Formation. Personality and Social Psychology Bulletin, 34, 692-705. https://doi.org/10.1177/0146167207313730

Kunda, Z., \& Sherman-Williams, B. (1993). Stereotypes and the Construal of Individuating Information. Journal of Personality and Social Psychology, 19, 90-99. https://doi.org/10.1177/0146167293191010

Kunda, Z., \& Thagard, P. (1996). Forming Impression from Stereotypes, Traits, and Behaviors: a Parallel Constraint Satisfaction Theory. Psychological Review, 103, 294-308. https://doi.org/10.1037/0033-295X.103.2.284

Kunda, Z., \& Thagard, P. (1997). Making Sense of People: Coherence Mechanism. http://cogsci.uwaterloo.ca/Articles/Pages/Making.Sense.html

Locksley, A., Borginda, E., Brekke, N., \& Hepburn, C. (1980). Sex Stereotypes and Social Judgment. Journal of Personality and Social Psychology, 39, 821-831. https://doi.org/10.1037/0022-3514.39.5.821

Locksley, A., Hepburn, C., \& Ortiz, V. (1982). Social Stereotypes and Judgments of Individuals: An instance of the Base Rated Fallacy. Journal of Experimental Social Psychology, 18, 23-42. https://doi.org/10.1016/0022-1031(82)90079-8

Macrae, C. N., \& Bodenhausen, G. V. (2001). Social Cognition: Categorical Person Per- 
ception. British Journal of Psychology, 92, 239-255.

https://doi.org/10.1348/000712601162059

Martin, D., \& Macrae, C. N. (2007). A Face with a Cue: Exploring the Inevitability of Person Categorization. European Journal of Social Psychology, 37, 806-816. https://doi.org/10.1002/ejsp.445

Mettrick, J., \& Cowan, G. (1996). Individuating Information, Gender, and the 1995 America's Cup. Journal of Social Behavior and Personality, 11, 399-410

Nauts, S., Langner, O., Huijsmans, I., Vonk, R., \& Wigboldus, D. H. J. (2014). A Replication and Review of Asch's (1946) Evidence for a Primacy-of-Warmth Effect in Impression Formation. Social Psychology, 45, 153-163.

Popov, A., Parker, L., \& Seath, A. (2018). Schema Theory. Psychology (2nd ed., pp. 148). Oxford.

Pratto, F., \& Bargh, J. A. (1991). Stereotyping Based on Apparently Individuating Information: Trait and Global Components of Sex Stereotypes under Attention Overload. The Journal of Experimental Social Psychology, 27, 26-47. https://doi.org/10.1016/0022-1031(91)90009-U

Quinn, K. A., \& Macrae, C. N. (2005). Categorizing Others: The Dynamics of Person Construal. Journal of Personality and Social Psychology, 88, 467-479. https://doi.org/10.1037/0022-3514.88.3.467

Quinn, K. A., Mason, M. F., \& Macrae, C. N. (2009). Familiarity and Person Construal: Individuating Knowledge Moderates the Automaticity of Category Activation. European Journal of Social Psychology, 39, 852-861. https://doi.org/10.1002/ejsp.596

Read, S. J., Vamnan, E. J., \& Miller, L. C. (1997). Connectionism, Parallel Constraint Satisfaction Processes, and Gestalt Principles: (Re) Introducing Cognitive Dynamics to Social Psychology. Personality and Social Psychology Review, 1, 26-53.

https://doi.org/10.1207/s15327957pspr0101_3

Richey, M. H., Mcclelland, L., \& Shimkunas, A. M. (1967). Relative Influence of Positive and Negative Information in Impression Formation and Persistence. Journal of Personality and Social Psychology, 6, 322-327. https://doi.org/10.1037/h0024734

Tobin, S. J., Weary, G., Brunner, R. P., Gonzales, J., \& Han, A. (2009). Causal Uncertainty and Stereotype Avoidance: The Role of Perceived Category Fit. Social Cognition, 27, 917-928. https://doi.org/10.1521/soco.2009.27.6.917 